\title{
Perfil hematológico de cães em diferentes concentrações de anticoagulante e bioquímica sérica em tempos diferentes de armazenamento*
}

\section{Hematologic profile of dogs in different concentrations of anticoagulant and serum biochemistry at different storage times}

\author{
Ivana Cristina Nunes Gadelha, ${ }^{* *}$ Maria Vanuza Nunes de Meireles, ${ }^{* *}$ Erica Natália Bessa, ${ }^{* *}$ Higina Moreira Melo, ${ }^{* *}$ \\ Erinaldo Freire de Amorim, ${ }^{* *}$ Leonardo Lelis de Macedo Costa**
}

\begin{abstract}
Resumo
O objetivo deste estudo foi verificar as alterações hematológicas e bioquímicas em amostras sanguíneas de cães, em diferentes concentrações de anticoagulante EDTA- $\mathrm{Na}_{2}$ e diferentes tempos de armazenamento em temperatura entre 4 e $8^{\circ} \mathrm{C}$ por até 48 horas. Para isso, foram coletados $12 \mathrm{~mL}$ de sangue por venopunção jugular ou cefálica de 30 cães (Canis lupus familiaris), procedentes do atendimento clínico realizados no Hospital Veterinário da UFERSA - Mossoró-RN. As amostras foram distribuídas em 4 tubos de ensaio, sendo 3 tubos contendo $50 \mathrm{uL}$ de EDTA-Na ${ }_{2}$ para a análise hematológica, preenchidos com $1 \mathrm{~mL}, 3 \mathrm{~mL}$ e $4 \mathrm{~mL}$, e o quarto tubo, para análise bioquímica, sem anticoagulante, foi acondicionado $4 \mathrm{~mL}$ da amostra. As análises foram realizadas durante a primeira hora, 24 e 48 horas após a coleta. Posteriormente às análises, observou-se que as variáveis hematológicas se mostraram estáveis ao longo do tempo e independente da concentração de anticoagulante, sem diferenças significativas. Os resultados revelaram que a relação sangue/anticoagulante não interfere nos parâmetros do hemograma quando mantidas em condições adequadas de armazenamento e processadas em analisador hematológico Scil Vet abc ${ }^{\mathrm{TM}}$. Quanto às análises bioquímicas, submetidas às mesmas condições de armazenamento, também se mostraram estáveis por até 48 horas. Desse modo, conclui-se que as amostras sanguíneas podem ser armazenadas entre $4^{\circ} \mathrm{C}$ e $8^{\circ} \mathrm{C}$ por até 48 horas.
\end{abstract}

Palavras-chave: Canino, EDTA, estocar, sangue, soro.

\begin{abstract}
The objective of this study was to verify hematological and biochemical alterations in blood samples from dogs, in different concentrations of anticoagulant EDTA- $\mathrm{Na}_{2}$ and different storage times in temperature between 4 and $8^{\circ} \mathrm{C}$ for up to 48 hours. For this, $12 \mathrm{~mL}$ of blood were collected by jugular or cephalic venipuncture from 30 dogs (Canis lupus familiaris), from the clinical care performed at the Veterinary Hospital of UFERSA - Mossoró-RN. The samples were distributed in 4 test tubes, 3 tubes containing 50uL of EDTA-Na ${ }_{2}$ for the hematological analysis, filled with $1 \mathrm{~mL}, 3 \mathrm{~mL}$ and $4 \mathrm{~mL}$, and the fourth tube, for biochemical analysis, without anticoagulant, was conditioned $4 \mathrm{~mL}$ of the sample. The analyzes were performed during the first hour, 24 and 48 hours after collection. Subsequent to the analyzes, it was observed that the hematological variables were stable over time and independent of the anticoagulant concentration, without significant differences. The results showed that the blood / anticoagulant ratio did not interfere in the hemogram when stored under adequate conditions of storage and processed in a hematology analyzer Scil Vet abc ${ }^{\mathrm{TM}}$. As for the biochemical analyzes, submitted to the same storage conditions, they were also stable for up to 48 hours. Thus, it is concluded that blood samples can be stored between $4^{\circ} \mathrm{C}$ and $8^{\circ} \mathrm{C}$ for up to 48 hours.
\end{abstract}

Keywords: Canine, EDTA, stok, blood, serum

\section{Introdução}

A confiabilidade dos resultados liberados por laboratórios de análises clínicas é primordial, uma vez que as informações obtidas em medicina veterinária influenciam de forma ampla nas decisões dos clínicos e na conduta terapêutica para seus pacientes (GUIMARÃES et al., 2011).
Vários fatores contribuem para a má qualidade das amostras hematológicas, dentre eles a quantidade de sangue nos tubos de coleta, alterando a relação sangue/anticoagulante (OLIVEIRA et al., 2010). Os anticoagulantes são substâncias químicas que impedem a coagulação sanguínea e adiam a deterioração celular, contudo estão entre os maiores causadores de alterações na morfologia dos eritrócitos (ALMEIDA et al., 2012).

*Recebido em 17 de fevereiro de 2017 e aceito em 23 de março de 2018.

**Universidade Federal Rural do Semi Árido

Autor para correspondência: ivanacris@ufersa.edu.br 
O ácido etilenodiaminotetracétito (EDTA) é o anticoagulante mais utilizado para análises hematológicas, pois não interfere na morfologia celular, conservando-a por até 24 horas quando refrigerado adequadamente (ALMEIDA et al., 2012; THRALL et al., 2015).

Além disso, os exames bioquímicos, analisados a partir do soro e plasma sanguíneos são importantes ferramentas para auxiliar no diagnóstico de diversas doenças que acometem os animais domésticos (KANEKO et al., 1997; SPINELLI et al., 2012).

A adequada interpretação dos resultados da análise dos compostos bioquímicos do sangue depende de vários fatores que abrangem a estabilidade das amostras nos testes. Esses fatores estão agregados ao processamento e dosagem de alguns metabólitos, que estão relacionados com a dieta alimentar, o tempo e a temperatura de armazenamento da amostra (SPINELLI et al., 2012). Portanto, vê-se a importância de se padronizar um período e condições de armazenamentos para a realização de testes bioquímicos após a coleta.

Rotineiramente boa parte dos exames laboratoriais solicitados na clínica médica veterinária, não pode ser realizado, devido à inadequação das amostras enviadas ao laboratório. Diante disso, este trabalho foi proposto com objetivo de verificar as alterações hematológicas em amostras de sangue de cães com diferentes concentrações de anticoagulante EDTA- $\mathrm{Na}_{2}$ em diferentes tempos de armazenamento, como também, avaliar a influência do tempo de armazenamento em temperatura de 4 a $8^{\circ} \mathrm{C}$, de amostras de soro de cães na determinação sérica de alanina aminotransferase, aspartato aminotransferase, proteínas totais, albumina, fosfatase alcalina, gama-glutamiltransferase, ureia e creatinina, já que alterações errôneas podem interferir na conduta clínica do médico veterinário.

\section{Material e métodos}

Foram coletadas amostras sanguíneas de 30 cães (Canis lupus familiaris) de diferentes raças, adultos (a partir de um ano de vida), com peso acima de $20 \mathrm{Kg}$, procedentes do atendimento clínico realizados no Hospital Veterinário da UFERSA. Os proprietários foram informados sobre os objetivos da pesquisa e assinaram um Termo de Consentimento Livre e Esclarecido.

Foram coletados, de maneira asséptica, $12 \mathrm{~mL}$ de sangue por venopunção jugular ou cefálica com auxílio de seringa (DESCARPACK®). A amostra de sangue foi dividida em 4 tubos de ensaio sendo 3 tubos contendo $50 \mu \mathrm{L}$ de ácido etilenodiaminotetracétito-sódico (EDTA-Na ${ }_{2}$ ) 300mmol/L (Bioclin), preenchidos com $1 \mathrm{~mL}, 3 \mathrm{~mL}$ e $4 \mathrm{~mL}$ e no quarto tubo, sem anticoagulante, foram colocados $4 \mathrm{~mL}$ da amostra para obtenção de soro. As coletas seguiram as boas práticas recomendadas por Diehl e colaboradores, 2001.

As amostras foram devidamente identificadas e enviadas para o Laboratório de Patologia Clínica Veterinária do Hospital Veterinário da UFERSA, e após a primeira análise as amostras foram mantidas a uma temperatura entre 4 a $8^{\circ} \mathrm{C}$. Cada amostra foi analisada três vezes, sendo a primeira análise realizada durante a primeira hora (momento 0 h) após a amostragem, e sucessivamente, em 24 e 48 horas. Para a obtenção dos valores de hemácias, hematócrito, hemoglobina, plaquetas e contagem total de leucócitos, processou-se as amostras sanguíneas no analisador hematológico Scil Vet $a b c^{\mathrm{TM}}$, após homogeneização de 15 minutos. Para avaliação morfológica das células, foram realizadas extensões sanguíneas logo após a coleta do sangue em EDTA- $\mathrm{Na}_{2}$, para as amostras analisadas no momento $\mathrm{Oh}$, e para as amostras avaliadas 24 e 48 horas após a coleta, as extensões só foram confeccionadas após atingirem a temperatura ambiente. As mesmas foram coradas com Panótico rápido $®$ (Renilab, Brasil) e examinadas através de microscopia óptica em aumento de 400x e 1000x. As amostras mantidas sob refrigeração por 24 e 48 horas, só foram processadas após homogeneização e atingir a temperatura ambiente.

Para as análises bioquímicas, as amostras sem anticoagulante foram centrifugadas (3000 rpm, durante 2 minutos) e o soro extraído, para posterior análise bioquímica. Os parâmetros ALT (alanina aminotransferase), AST (aspartato aminotransferase), URE (concentração de nitrogênio uréico), PT (proteínas totais) e albumina (ALB) foram processados no aparelho de bioquímicas HUMAN STAR 80 (InVitro). Os parâmetros ALP (fosfatase alcalina), GGT (gama-glutamiltransferase) e CRE (creatinina) que foram analisadas no equipamento Bioplus 2000 (São Paulo, Brasil), sendo utilizados kits reagentes (Vida Biotecnologia Ltda - ME - BRASIL). A concentração de globulinas foi obtida através da subtração do valor total da proteína pela concentração de albumina. O restante do soro extraído foi refrigerado a uma temperatura de 4 a $8^{\circ} \mathrm{C}$, para realização das mesmas análises bioquímicas em 24 e 48 horas após a coleta.

Os dados obtidos foram dispostos na forma de média e desvio padrão, para cada grupo (0h, $24 \mathrm{~h}$ e $48 \mathrm{~h}$ ) de acordo com o momento em que foram realizadas as análises, considerando-se o grupo controle aquele em que as análises foram realizadas imediatamente após a coleta (momento Oh). Desta forma, foi realizada distribuição inteiramente casualizada, a análise da variância e as médias comparadas entre si pelo teste de Tukey a $5 \%$ de probabilidade pelo programa de análise estatística software R.

\section{Resultados e discussão}

As variáveis hematológicas mostraram-se estáveis ao longo do tempo e independente da concentração de anticoagulante, sem diferenças estatísticas significativas, mesmo 48 horas após a coleta da amostra. De tal modo, o hematócrito revelou uma variação máxima de $1,8 \%$, em relação a concentração de anticoagulante, comparadas com o mesmo tempo de armazenamento e de $0,7 \%$ nos diferentes tempos de armazenamento, dentro do conjunto com a mesma concentração de EDTA-Na ${ }_{2}$ (Figura 1). Portanto, a maior diferença foi quanto ao volume de sangue coletado e sua proporção com EDTA-Na2 e não com relação ao tempo que este fica armazenado até seu processamento, embora não mostrasse diferença estatística. 


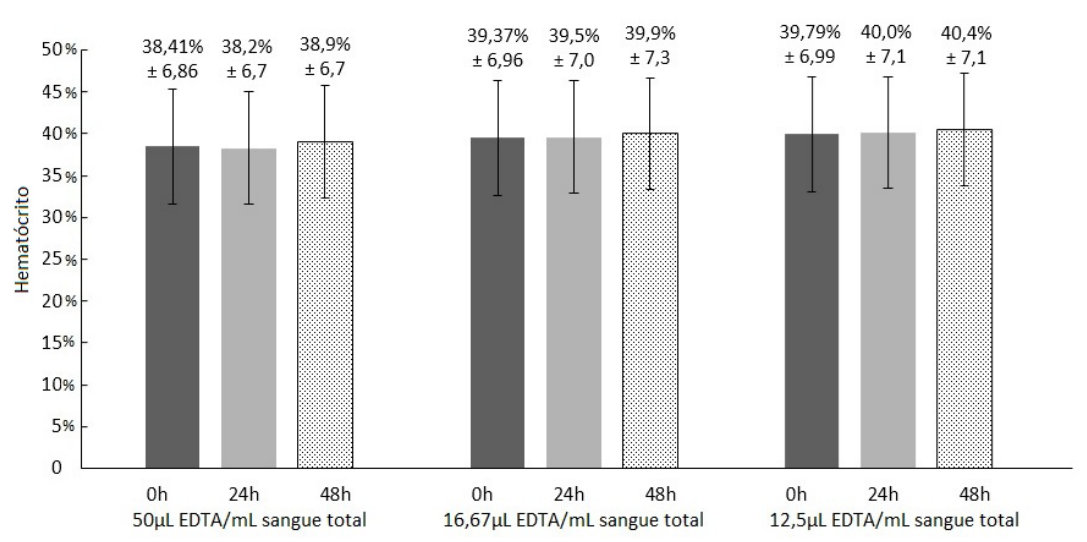

Figura 1: Média e desvio padrão dos valores do hematócrito em sangue de cães com diferentes concentrações de EDTA- $\mathrm{Na}_{2}$, realizados em diferentes tempos após a coleta $(p<0,05)$.
$\mathrm{Na}$ dosagem de hemoglobina as médias obtiveram variação máxima de $0,49 \mathrm{~g} /$ $\mathrm{dL}$ entre as diferentes concentrações de anticoagulante e de $0,4 \mathrm{~g} / \mathrm{dL}$ nos diferentes tempos de armazenamento (Tabela 1). Quanto à contagem de hemácias, não variou mais do que 0,19 milhões $/ \mathrm{mm}^{3}$ para a concentração de anticoagulante e 0,08 milhões $/ \mathrm{mm}^{3}$ ao longo do tempo (Tabela 1).

Trabalhos anteriores também detectaram a ausência de alterações significativas nas variáveis hematológicas ao longo do tempo (FREISE et al., 2009). Em um experimento similar, Oliveira (2009) também detectou estabilidade dos valores de hemácias, hematócrito e hemoglobina ao longo do tempo

Tabela 1: Médias e desvio padrão de parâmetros hematológicos de cães em diferentes concentração de anticoagulante e ao longo do tempo de armazenamento $(p<0,05)$

\begin{tabular}{|c|c|c|c|c|c|c|c|c|c|}
\hline $\begin{array}{r}\text { Tempo em } \\
\text { horas }\end{array}$ & & 0 & & & 24 & & & 48 & \\
\hline $\begin{array}{c}\text { Volume de } \\
\text { sangue/EDTA }\end{array}$ & $1 \mathrm{~mL}$ & $3 \mathrm{~mL}$ & $4 \mathrm{~mL}$ & $1 \mathrm{~mL}$ & $3 \mathrm{~mL}$ & $4 \mathrm{~mL}$ & $1 \mathrm{~mL}$ & $3 \mathrm{~mL}$ & $4 \mathrm{~mL}$ \\
\hline $\begin{array}{c}\text { Hemácias } \\
\left(\text { milhões } / \mathrm{mm}^{3}\right)\end{array}$ & $6,08 \pm 1,04$ & $6,20 \pm 1,07$ & $6,26 \pm 1,08$ & $6,06 \pm 1,03$ & $6,15 \pm 1,10$ & $6,25 \pm 1,07$ & $6,07 \pm 1,05$ & $6,13 \pm 1,06$ & $6,18 \pm 1,05$ \\
\hline $\begin{array}{l}\text { Hemoglobina } \\
\text { (g/dL) }\end{array}$ & $13,50 \pm 2,42$ & $13,84 \pm 2,56$ & $13,994 \pm 2,55$ & $13,57 \pm 2,36$ & $13,86 \pm 2,49$ & $14,00 \pm 2,46$ & $13,57 \pm 2,30$ & $13,87 \pm 2,48$ & $13,6 \pm 3,4$ \\
\hline
\end{tabular}

e da concentração de EDTA. Segundo Thrall et al. (2015), amostras contendo excesso de EDTA, resulta em falsa redução do hematócrito e do VCM, quando utilizado o método de microhematócrito. Deste modo, tal resultado pode ser atribuído à metodologia adotada, bem como ao manuseio adequado das amostras, visto que as mesmas foram acondicionadas sob refrigeração durante 48 horas, o que pode ter auxiliado a preservação dos constituintes celulares.

Com relação aos resultados apresentados para contagem total de leucócitos (Figura 2) e plaquetas (Tabela 1), também não foram observadas diferenças estatísticas significantes, bem como se mantiveram dentro dos valores de referência, embora a contagem total de leucócitos tenha mostrado uma discreta variação das médias, não interferindo nos resultados do exame. Estudos realizados por Dalanhol et al. (2010), analisando sangue humano também obtiveram achados semelhantes para contagem de leucócitos, já em relação a contagem de plaquetas observaram diferença significativa tanto nas amostras avaliadas em temperatura ambiente quanto em temperatura de $4^{\circ} \mathrm{C}$, com uma atenção maior para o tempo de armazenamento de 72 horas, sendo atribuído a presença de agregação plaquetária.

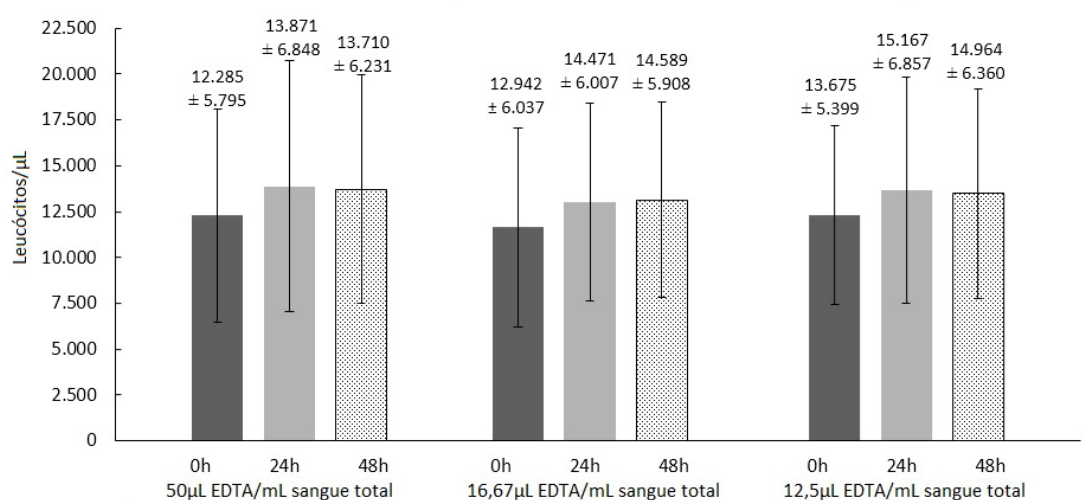

Figura 2: Médias e desvio padrão da contagem de leucócitos totais em amostras de sangue de cães em diferentes concentrações de EDTA- $\mathrm{Na}_{2}$, realizados em diferentes tempos após a coleta $(p<0,05)$
Ao avaliar a disposição das plaquetas, verificouse agregação plaquetária nos esfregaços sanguíneos confeccionados com sangue após 24 horas da coleta, em todas as concentrações de EDTA- $\mathrm{Na}_{2}$. Quanto aos dados referentes a morfologia dos leucócitos, não foram quantificados para análise no estudo.

Hlavac (2012), também observou ausência de alteração na contagem de plaquetas em amostras de sangue coletas com EDTA e armazenadas a $4^{\circ} \mathrm{C}$. Contudo, foi observado maior variação na agregação plaquetária quando comparados os tempos $0 \mathrm{~h}$ e $6 \mathrm{~h}$. Franco e colaboradores (2007), identificaram que amostras mantidas sob refrigeração durante 12 horas, tiveram menores valores de 
leucócitos e plaquetas totais. Corroborando com nossos estudos, ao analisar a influência da concentração de anticoagulante, tempo e temperatura de armazenagem sobre os parâmetros hematológicos no hemograma automatizado, Oliveira et al. (2010) observaram que amostras sanguíneas, conservadas à temperatura de 2 a $8^{\circ} \mathrm{C}$ por 48 horas, permaneceram em condições adequadas para análise. $\mathrm{O}$ que permite acreditar que as condições a que foram submetidas as amostras, a partir da coleta e durante o armazenamento, tenham contribuído para este resultado, visto que, após a coleta foram imediatamente processadas, não passando por nenhum tipo de transporte que inviabilizasse tal análise.

O armazenamento de amostras para dosagens bioquímicas é considerado usual na rotina clínica veterinária, dessa forma, enzimas séricas necessitam de considerações especiais para armazenamento. Uma regra geral é que, para maior confiabilidade, a atividade enzimática no soro deve ser determinada em $24 \mathrm{~h}$ a partir da coleta e separação do soro por centrifugação. Não se recomenda arquivar material por longos períodos para a determinação da atividade enzimática no soro. Dados sobre a estabilidade exata da atividade enzimática sérica, sob várias condições de armazenamento, são difíceis de interpretar (THRALL et al., 2015). Contudo, um quesito que necessita ser avaliado é a padronização de métodos para o manuseio e armazenamento de amostras, pois o processamento indevido interfere na concentração das substâncias podendo ocorrer resultados inconsistentes ou conclusões errôneas. Por isso, a forma de armazenamento é importante para obter um resultado final confiável (SPINELLI et al., 2012).

Verificou-se que ao longo do tempo de armazenamento do soro, separado do coágulo após centrifugação, sob refrigeração entre 4 e $8^{\circ} \mathrm{C}$ durante 24 e 48 horas, não houve diferença significativa na determinação da enzima ALT (Tabela 2), isso pode ocorrer porque a meia-vida sérica dessa enzima em cães é de 17 a 60 horas (THRALL et al., 2015). Segundo Rosato (2007) a atividade sérica desta enzima não sofreu alteração até sete e 30 dias estocados a $25^{\circ} \mathrm{C}$ e $4^{\circ} \mathrm{C}$, respectivamente. Então, as formas de acondicionamento das amostras no estudo permitem a estabilidade da enzima.

Os valores obtidos para a atividade sérica de AST evidenciaram a estabilidade durante os testes (Tabela 2), resultado semelhante ao estudo de Rosato (2007), onde não houve variação do parâmetro por sete dias nas amostras de soro mantidas a $25^{\circ} \mathrm{C}$; 30 dias, quando armazenadas a $4^{\circ} \mathrm{C} ; 90$ dias, estocadas a $-4^{\circ} \mathrm{C}$ ou $-20^{\circ} \mathrm{C}$; e apenas 15 dias, quando a $-70^{\circ} \mathrm{C}$. Porém, González

Tabela 2: Médias e desvio padrão dos níveis séricos caninos de ALT, AST, ALP, GGT na Oh, 24h e 48 h após coleta, armazenado em temperatura variando entre 4 e $8^{\circ} \mathrm{C}(p<0,05)$ e valores de referência

\begin{tabular}{lrrrr}
\hline Horas & \multicolumn{1}{c}{0} & \multicolumn{1}{c}{24} & \multicolumn{1}{c}{48} & \multicolumn{1}{c}{$\begin{array}{c}\text { Valores de } \\
\text { Referências }\end{array}$} \\
\hline ALT (UI/L) & $36,4 \pm 11,1$ & $39,6 \pm 11,9$ & $38,4 \pm 12,8$ & $21-73^{*}$ \\
AST (UI/L) & $34,51 \pm 10,3$ & $38,2 \pm 9,5$ & $39,4 \pm 10,6$ & $21-45^{*}$ \\
ALP (UI/L) & $145,7 \pm 80,7$ & $163,9 \pm 79$ & $170,1 \pm 79,3$ & $9,4-249^{*}$ \\
GGT (UI/L) & $8,1 \pm 5,8$ & $9,6 \pm 6,6$ & $9,4 \pm 6,3$ & $1,3-10^{*}$ \\
\hline
\end{tabular}

* (KANEKO et al., 1997) e Silva (2003) descrevem que a temperatura de armazenamento pode causar instabilidade deste analito por comprometer a atividade desta enzima, já que a mesma possui meia vida em torno de 18 horas em temperatura ambiente. Com os resultados encontrados neste trabalho pode se inferir que este analito é estável por até 48 horas, quando mantidos em temperatura variando de 4 a $8^{\circ} \mathrm{C}$.

De acordo com os dados estatísticos referentes à ALP não houve diferenças significativas nos diferentes momentos da avaliação (Tabela 2). Sendo considerados valores normais para a espécie canina pelo método cinético, níveis séricos de fosfatase alcalina total entre 9,4-249UI/L (KANEKO, 1997). No estudo de Rosato (2007), a atividade sérica dessa enzima manteve-se estável por sete e 30 dias, quando amostras armazenadas a $25^{\circ} \mathrm{C}$ e $4^{\circ} \mathrm{C}$, respectivamente, e quando submetidas a congelamento, houve estabilidade por até 90 dias. Confirmando que a concentração da ALP se mantem confiável para análises posteriores a coleta, desde que bem acondicionadas.

Sendo a GGT mais específica, porém menos sensível que ALP, a determinação concomitante das duas enzimas de indução é mais confiável no diagnóstico de doenças hepato-biliar do que medidas isoladamente (THRALL et al., 2015). Nesse estudo, a atividade sérica de GGT não apresentou alteração significativa (Tabela 2), confirmando com Rosato (2007) que a atividade dessa enzima se apresentou estável por sete dias a $25^{\circ} \mathrm{C}$ e por 15 dias a $4^{\circ} \mathrm{C}$.

Os dois principais tipos de proteínas são albumina e globulinas, sendo a albumina a mais abundante (THRALL et al., 2015). No presente estudo, verificou-se que a média dos valores de proteína foi superior aos valores normais indicados por Meyer et al. (1995) e Kaneko et al. (1997), que consideram dentro da normalidade o intervalo de 5,4 a 7,7 g/dL (Figura 3).

A concentração sérica de proteína manteve-se estável durante este experimento, corroborando com os dados obtidos por Rosato (2007) onde, as amostras de soro foram mantidas por $25^{\circ} \mathrm{C}$ e $4^{\circ} \mathrm{C}$ durante sete dias e permaneceram inalteradas. Do mesmo modo, a albumina não apresentou alterações, sendo possível o armazenamento sem modificação significativa dos resultados (Figura 3).

Os níveis de ureia sérica não apresentaram diferença significativa (Tabela 3) sendo o mesmo observado por Rosato (2007) utilizando soro estocado a $4^{\circ} \mathrm{C}$ por até 15 dias para a espécie canina. Todavia, esses mesmos autores verificaram que a $25^{\circ} \mathrm{C}$ o analito em questão apresentou instabilidade após 8 horas da coleta. No estudo de Fernandes et al. (2001) foi constatado que amostras poderão ser analisadas até $24 \mathrm{~h}$ ou mais, quando mantidas em temperatura ambiente $\left(25^{\circ} \mathrm{C}\right)$ ou por 30 dias ou mais na temperatura entre 2 e $8^{\circ} \mathrm{C}$, sendo o soro mais estável que o plasma em todas as condições de estoque estabelecidas.

Os níveis de creatinina também não apresentaram diferença significativas (Tabela 3). Segundo Fernandes et al. (2001) e Rosato (2007), não foram observadas alterações deste metabólito quando as amostras foram refrigeradas $\left(2\right.$ a $\left.8^{\circ} \mathrm{C}\right)$ até 30 dias após a coleta.

Formas de armazenamento são fatores conhecidos por interferir os níveis aferidos, porém muitos relatos 


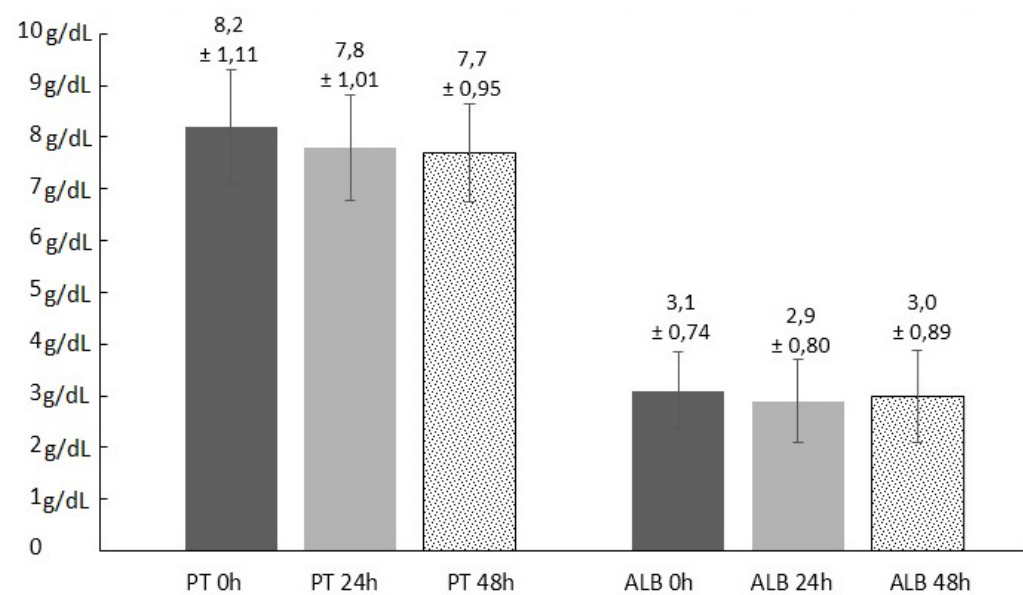

Figura 3: Média e desvio padrão dos níveis séricos caninos de PT e ALB na 0 h, 24h e 48h após coleta, armazenado em temperatura variando entre 4 e $8^{\circ} \mathrm{C}(p<0,05)$.

Tabela 3: Média e desvio padrão dos níveis séricos caninos de CRE e URE na $0 \mathrm{~h}, 24 \mathrm{~h}$ e $48 \mathrm{~h}$ após coleta, armazenado em temperatura variando entre 4 e $8^{\circ} \mathrm{C}(p<0,05)$ e valores de referência

\begin{tabular}{lcccc}
\hline Horas & Oh & 24h & $48 \mathrm{~h}$ & $\begin{array}{c}\text { Valores de } \\
\text { Referência }\end{array}$ \\
Analitos & & & & $1,02 \pm 0,18$ \\
\hline CRE $(\mathrm{mg} / \mathrm{dL})$ & $0,98 \pm 0,19$ & $1,01 \pm 0,14$ & $0,5-1,5^{*}$ \\
URE $(\mathrm{mg} / \mathrm{dL})$ & $31,62 \pm 8,8$ & $31,72 \pm 8,6$ & $32,67 \pm 8,9$ & $21,4-60^{*}$ \\
\hline
\end{tabular}

* (KANEKO et al., 1997).

\section{Referências}

ALMEIDA, M.S.; MELO, C.X.; ALMEIDA, M.M.C. Causas de alterações morfológicas nos glóbulos vermelhos que comprometem o resultado do laudo clínico. Facene/Famene, v. 10, n. 1, p. 83-90, 2012.

DALANHOL, M.; BARROS, M.; MAZUCHELLI, J.; SILVA, P. H.; HASHIMOTO, Y.; LARGURA, A. Efeitos quantitativos da estocagem de sangue periférico nas determinações do hemograma automatizado. Revista Brasileira de Hematologia e Hemoterapia. Paraná, v. 32, nº 1, p. 16- 22, 2010.

DEVANAPALLI, B.; BERMINGHAM, M.A.; MAHAJAN, D. Effect of long-term storage at $-80^{\circ} \mathrm{C}$ on the various lipid parameters in stored plasma samples. Clinica Chimica Acta, Charlottesville, v. 3, n. 322, p. 179-181, 2002.

DIEHL, K.H.; HULL, R.; MORTON, D.; PFISTER, R.; RABEMAMPIANINA, Y.; SMITH, D.; VIDAL J.M.; VAN DE VORSTENBOSCH, C. A good practice guide to the administration of substances and removal of blood, including routes and volumes. Journal of Applied Toxicology, v. 21, n. 1, p. 15-23, 2001.

FERNANDES, S. T.; TEIXEIRA, M. N.; SANTOS, E. S. Influência da temperatura e do tempo de armazenamento nas dosagens bioquímicas de ureia e creatinina em soro ou plasma caninos. Arquivo Brasileiro de Medicina Veterinária e Zootecnia, Belo Horizonte, v. 53, n. 6, p. 648-651, 2001.

FRANCO, D.F.; De NEGRI, D.; REMUSKA, R.D.; ALVES, M.L.; SACCO, S.R. Alterações no hemograma de cães causadas pela refrigeração da amostra. Revista Científica Eletrônica de Medicina Veterinária, v. 4, n. 8, 2007. Disponível em <http://faef. revista.inf.br/imagens_arquivos/arquivos_destaque/9x1qxorKeR3 kgrc_2013-5-21-16-40-29.pdf>. Acesos em 16jul2017. não são consistentes, e variam de decréscimo, não alteração ou acréscimo na concentração de substâncias (DEVANAPALLI et al., 2002). De acordo com Russel e Roussel (2007), a estabilidade dos analitos varia, mas a maioria é estável em temperatura de refrigeração $\left(4^{\circ} \mathrm{C}\right)$ por 24 a 36 horas, e, se um prazo mais longo for necessário antes que a amostra possa ser processada, o soro pode ser congelado a $-20^{\circ} \mathrm{C}$. Porém, no nosso estudo, pode-se constatar que esse tempo pode ser prolongado para 48 horas, sem alterações significativas das substâncias analisadas.

\section{Conclusões}

As amostras sanguíneas obtidas de cães, quando conservadas em EDTA- $\mathrm{Na}_{2}$, nas concentrações estudadas, armazenadas em temperatura de refrigeração e processadas em analisador hematológico até 48 horas após a coleta, não apresentaram alterações significativas nas análises quantitativas eritrocitárias, na plaquetometria e da leucometria global.

Analitos séricos permaneceram estáveis quando o soro foi armazenado a temperatura entre $4^{\circ} \mathrm{C}$ e $8^{\circ} \mathrm{C}$, até 48 horas após a coleta, conferindo uma maior segurança ao clínico que necessitar estocar amostras para posterior análise.
FREISE, K. F.; SCHMIDT, R.L.; GINGERICH, E.L.; VENGPEDERSEN, P.; WIDNESS, J.A. The effect of anticoagulant, storage temperature and dilution on cord blood hematology parameters over time. International Journal of Laboratory Hematology. v. 31, n. 5, p. 496-504, 2009.

GONZÁLEZ, F.H.D.; SILVA, S.C. Introdução à bioquímica clínica veterinária. Porto Alegre: UFRGS, 2003.

GUIMARÃES, A.C.; WOLFART, M.; BRISOLARA, M.L.L.; DANI, C. O Laboratório Clínico e os Erros Pré-analíticos. Revista HCPA, v.31, n.1, p. 66-72, 2011.

KANEKO, J.J.; HARVEY, J.W.; BRUSS, M.L. Clinical biochemistry of domestic animals. San Diego: Academic Press, 1997.198 p.

MEYER, D.J.; COLES, E.H.; RICH, L.J. Medicina de laboratório veterinário interpretação e diagnóstico. São Paulo: Roca, 1995.

OLIVEIRA, A. C.; RIBEIRO FILHO, J.D.; GUIMARÃES, J.D; SILVA, A.R.; DANTAS, W.M.F; BONFÁ, L.P.; FARIAS, S.K. Concentração de anticoagulante, tempo e temperatura de armazenagem sobre os parâmetros hematológicos no hemograma automatizado. Ciência Rural, Santa Maria, v. 40, n. 12, p. 2521-2526, dez. 2010.

OLIVEIRA, A.C. Influência da concentração do edta, tempo e temperatura de armazenagem sobre parâmetros hematológicos de cães no hemograma automatizado e manual. 2009. $48 \mathrm{f}$. Dissertação (Mestrado) - Curso de Pós-graduação em Medicina Veterinária, Universidade Federal de Viçosa, Viçosa, 2009.

ROSATO, P.N. Estabilidade de constituintes bioquímicos frente a diferentes temperaturas e períodos de estocagem, em amostras de soro de cães hígidos. 2007. XIII, 57 f. Dissertação (mestrado) - Universidade Estadual Paulista, Faculdade de Ciências Agrárias e Veterinárias, 2007. 
RUSSEL, K.E.; ROUSELL, A.J. Evaluation of the ruminant serum chemistry profile. Veterinary clinics of North America: Food Animal Practice, College of Veterinary Medicine and Biomedical Sciences, Texas A\&M University, Texas, v. 23, n. 3, p. 403-426. 2007.

SPINELLI, M.O.; CRUZ, R.J.; GODOY, C.M.S.C.; MOTTA, M.C. Efeito da temperatura e tempo no armazenamento de metabólitos no plasma de ratos Wistar recém desmamados. Revista da Sociedade Brasileira de Ciência em Animais de Laboratório, São Paulo, v. 1, n. 4, p. 317-321. 2012.
THRALL, M.A.; WEISER, G.; ALLISON, R.W.; CAMPBELL, T.W. Hematologia e bioquímica clínica veterinária. 2. ed. Rio de Janeiro: Guanabara Koogan, 2015. 